\title{
Climate Change - Facts and uncertainties
}

\section{G. Komen}

Ex-KNMI, Emeritus professor of Climate Dynamics, Institute for Marine and Atmospheric research Utrecht (IMAU), Utrecht University, the Netherlands. Internet: http://home.hetnet.nl/ g.j.komen. Email: g.j.komen@hetnet.nl

Manuscript received: September 2008; accepted: September 2008

\section{Introduction}

The Earth' climate is a complex system consisting of the atmosphere, the ocean and the land surface. This system receives energy from the sun. Latitudinal variations in insolation and the rotation of the Earth lead to a complex turbulent geophysical flow which induces important transports of heat and mass. Part of the solar radiation is reflected, the rest is radiated as long wave radiation. The radiative balance is complicated by atmospheric water vapour and other trace gases, clouds, heat transport and other factors.

Variability occurs on all time scales and with varying spatial patterns. At high temporal frequency we have intra- and interannual variability, with strong peaks on diurnal and annual timescales. At the other side of the spectrum, on geological time scales, there are also many significant fluctuations. Sometimes, it is possible to associate physical mechanisms with variability on particular temporal and spatial scales. Our mid-latitude weather, for example, results from instabilities in the jet stream which are a manifestation of the chaotic nature of atmospheric mid-latitude flow. On interannual time scales the El Niño Southern Oscillation is an important mode of global variability, involving interactions between the atmosphere and the ocean. On longer time scales feedbacks involving the biosphere also are a source of variability. Examples of other factors driving climatic variations are solar variability, major volcanic eruptions and variations in the orbital parameters of the earth. In recent years the human influence is a factor of growing importance through changes in atmospheric composition and through land surface change.

In general, climate variations are the result of many competing mechanisms. In such situations quantification is essential and numerical models are essential tools for their study. These models are not perfect, but over the past few decades model performance has been steadily increasing, as apparent from numerous intercomparison and validation studies. Data shortage remains an obvious bottleneck. Another bottleneck is the huge range of temporal scales from seconds to billions of years. No single model is able to describe all of these scales.

The 20th century is special because of the availability of instrumental observations. Models successfully simulated the main features of the circulation and in particular the observed evolution of the global mean temperature. This provided insight into the relative importance of different mechanisms. First it was found that the observed global temperature change is unusual, namely larger than one would expect on the basis of an estimate of natural fluctuations on this centennial time scale. Later insight in the cause of this behaviour emerged, when it was found that the observed warming could be reproduced by models if the human influence was taken into account, but not if this influence was neglected. Therefore, the observed change is not only unusual, but it can also be attributed in part to human influence. Obviously, these findings depend on the quality of the observations and the skill of the models, neither being perfect, and one should remember that it is always possible that the discovery of a new (so far unknown) mechanism might change the picture. Therefore, nothing is certain. This is in particular so for statements about possible future developments ${ }^{1}$.

The current public debate focuses very much on the 20th and 21st century. The Intergovernmental Panel on Climate Change, when compiling relevant scientific information for policy makers in its Fourth Assessment Report (2007), has

1 For a more extensive account of this view, see my weblog 'Uncertainties in climate prediction' on Climate Science (http://climatesci.org/2008/07/07/guest-weblogby-gerbrand-komen). 
made an impressive effort to quantify (un)certainties, often on the basis of (subjective) expert judgment. To illustrate their approach I have extracted a summary of robust findings and key uncertainties from chapter 6 of the Synthesis Report ${ }^{2}$ which follows below. The complexity of this message is striking. Both the scientific and the public debate would gain from a better awareness of this complexity.

\section{Observed changes}

\section{Robust findings}

1. Climate is warming.

2. Many observed physical and biological changes are consistent with this warming.

3. Greenhouse gas (GHG) concentrations far exceed pre-industrial values due to anthropogenic emissions.

4. Most warming over the past 50 years is very likely due to anthropogenic GHG increases. Part of the variation can be accounted for by natural causes.

5. Anthropogenic warming over the last three decades has likely had a discernible influence at the global scale on observed changes in many physical and biological systems.

\section{Key uncertainties}

1. Data limited in some regions (in particular data on changes in natural and managed systems).

2. Analysis and monitoring of changes in extreme events (droughts, tropical cyclones, extreme temperatures, and the frequency and intensity of precipitation).

3. Effects of climate changes on human and some natural systems difficult to detect (due to adaptation and nonclimatic drivers).

4. Understanding and attribution of observed temperature changes due to natural or human causes at smaller than continental scales (land- use change, pollution, model deficiency).

5. Magnitude of $\mathrm{CO}_{2}$ emissions from land-use change; $\mathrm{CH}_{4}$ emissions from individual sources.

\section{Future changes}

\section{Robust findings}

1. GHG emissions will grow in the next few decades.

2. For the next two decades a global mean warming trend of about $0.2^{\circ} \mathrm{C}$ per decade is projected for a range of SRES emission scenarios.

3. Warming + induced changes in the 21 st century very likely larger than those in the 20th century.
4. Stronger warming of land (than adjacent oceans) and northern high latitudes.

5. Positive $\mathrm{CO}_{2}$ feedback, from land surface and ocean processes.

6. Anthropogenic warming and sea level rise would continue for centuries.

7. Equilibrium climate sensitivity is very unlikely to be less than $1.5^{\circ} \mathrm{C}$.

8. Some systems, sectors and regions are likely to be especially affected by climate change. The systems and sectors are some ecosystems (tundra, boreal forest, mountain, mediterranean-type, mangroves, salt marshes, coral reefs and the sea-ice biome), low-lying coasts, water resources in dry tropics and subtropics and in areas dependent on snow and ice melt, agriculture in low-latitude regions, and human health in areas with low adaptive capacity. The regions are the Arctic, Africa, small islands and Asian and African mega-deltas.

9. Impacts will very likely increase due to increased frequencies and intensities of extreme weather events (heat waves, tropical cyclones, flood and drought). Vulnerability stronger than thought.

\section{Key uncertainties}

1. Climate sensitivity and emission trajectory required to achieve a particular stabilisation level.

2. Strength of feedbacks (clouds, oceanic heat uptake, carbon cycle); projections of e.g. precipitation at smaller scales.

3. Effect of aerosols.

4. Sea level: Greenland and Antarctic ice sheet dynamics, heating rate of ocean interior.

5. Large scale ocean circulation changes beyond the 21st century (melt water?).

6. Projections of climate change and its impacts beyond 2050 (scenario- and model dependence).

7. Impacts research is hampered by uncertainties in regional projections of climate change, particularly precipitation.

8. Net cost of climate change.

\section{Responses to climate change}

\section{Robust findings}

1. More extensive adaptation is required to reduce vulnerability to climate change.

2. Unmitigated climate change would, in the long term, be likely to exceed the capacity of natural, managed and human systems to adapt.

3. Mitigation is possible. Stabilisation at different GHG concentration levels can be achieved by deployment of a portfolio of technologies. For this to be successful barriers have to

2 See http://www.ipcc.ch/pdf/assessment-report/ar4/syr/ar4_syr.pdf. 
be removed and appropriate and effective incentives are necessary. In addition, further R\&D would be required to improve the technical performance, reduce the costs, and achieve social acceptability of new technologies.

4. To reduce risk it is better to start mitigation soon.

5. Making development more sustainable can help achieve mitigation and reduce vulnerability.

6. Decisions about macro-economic and other policies that seem unrelated to climate change can significantly affect emissions.

\section{Key uncertainties}

1. Integrated assessment of vulnerability and the use of climate information in planning process.

2. Adaptive and mitigative capacity (socioeconomic development pathways).

3. Costs of adaptation.

4. Estimates of mitigation costs range from net negative up to $100 \mathrm{US} \$ / \mathrm{t} \mathrm{CO}_{2}$-equivalent (innovation speed, lifestyle).

5. The effects of non-climate policies on emissions. 